Fournal of Information Technology (1992) 7, 187-188

\title{
Editorial
}

\section{Theme issue: Information technology and marketing}

Theme editors: Leslie Willcocks, Templeton College, Oxford, UK

Laurent Maruani HEC Graduate School of Management, Paris, France

For this special issue of the Journal the theme of Information Technology and Marketing has been interpreted broadly. We wanted to attract papers that reflected current interest and preoccupations in the area, rather than trying to stipulate what these might or should be. We outlined the subject area as how information and IT relate to, support or transform any or all marketing activities. This would include, for example, market and marketing research, organizing for marketing, relationships with customers, product innovation, promotional effort, pricing techniques and technologies, place and distribution channels, and marketing planning and decision-making. The theme also covers IT for improving competitiveness and furthering the organization's position in the marketplace and its service to customers/ clients/consumers. Our experience has been of major interest in this topic. In fact we attracted twenty suitable papers of which only eight can be published in this single issue. Others will appear in a book on the subject or in later issues of the Journal. Why this level of interest, and what are the themes authors are pursuing?

As Domegan and Donaldson argue in their paper in this issue, while the adoption levels of IT by marketing managers remain relatively low, a number of studies, including their own, show clear correlations between strong market orientation, extensive uses of information sources and effective use of IT. In an attempt to reduce costs, increase efficiency and create or sustain competitive position, one might posit definite moves toward exploiting IT in previously underdeveloped marketing areas. In practice this has not always happened; indeed recession in industrialized economies from 1900 may well have induced more cost cutting IT programmes, leaving marketing and customer service applications as low priority items. However there is a marked tension in most organizations between survival through cost containment and the need to expand revenue and retain, indeed increase the customer base. Assessments in organizations of how IT can be used inherits, and is located in, such tensions in business direction and objectives. As a result a great emphasis on cost containment in and through IT is matched by concerns to how, at the same time, IT can deliver business benefit, and underpin more customeroriented strategies. The papers based on survey work on
IT and marketing reflect these sorts of tensions. The rest of the papers show some ways out of such tensions through marketing uses of IT.

A major theme is that of service. This is dealt with in different ways in three papers. Thus Tony Rands, in a very rich paper, seeks to apply service and marketing concepts to the role of the IT function itself and its relationship to customers, however defined. His research suggests that the application of service concepts to IT marks an important departure from previously accepted methods of analysis, and yields new insights and methods for managing IT. Given the often discussed 'culture gap' between users and IT specialists/departments, he provides valuable insight into types of service product, customer contact, designing service delivery systems and improving service quality. Christine Domegan and Bill Donaldson report on how IT can be used to enhance service to external customers. Their study is based on research into nearly 70 organizations, including 20 'best practice' firms across Ireland, France and the UK. Similarities among practices in the three countries were strong. They found marketing uses of IT increasing over the last three years, and are expected to increase into the future. Their study is useful for showing how little of the IT potential in marketing and customer service is being utilized, but also what characterizes the leading edge companies in these areas.

Eric Brousseau and Bertrand Quélin deal with service in a different way; their paper focuses on developments in the markets for telecommunications services. Here their paper usefully distinguishes, in a sample of 125 services, three overall types of service - enhanced communication services, dedicated services and information services. They then identify for information services three subgroups, namely specialized communication, community, and on-line transaction services. They find that, against the traditional assumption in the economics literature of separation of users from the innovating unit, users of telecommunications services are frequently closely involved in development and production processes. This stems from their proprietary, relevant know-how - thus 'users' knowledge as a specific asset'.

Another focus of attention in the papers has been the developing role of computerized marketing databases 
(CMDs). Two papers deal with this explicitly. Thus Ross Cameron and David Targett provide details of a 60 organization survey into current and future usage of CMDs. They found a high proportion of organizations using such databases, but a number of problem areas and barriers to their further utilization, both from the supplier and user sides. Stephen Flowers provides a more detailed example of how a database marketing system can be used innovatively. His example is the Vision system, an interactive multi-media point of sale system being used in retail marketing in the US. He also discusses its application for micromarketing, that is highly targetted marketing at the individual household level, and the implications this will have for manufacturers and the marketing industry as a whole. In support of the notion that retailing may be seeing many of the more innovative uses of IT for marketing purposes, Jonathan Reynolds discusses, with examples, how IT can support key locational decisions, and how geo-demographic information systems can improve decision-making in relation to branch portfolios. $\mathrm{He}$ also usefully discusses likely future issues which will confront practitioners in these areas.

A further theme is internationalization. Charles Steinfield, Laurence Caby and Pierre Vialle contribute to this issue by analysing the potential uses and impacts of videotex for international business applications. Their review of eight firms shows four main strategies used to exploit videotex internationally. They also show how videotex usage can shift transaction costs away from the service provider, create a more expanded base of partners and more standardized interactions with these. In some cases videotex enabled firms to access foreign markets previously too expensive to reach. A final paper points also to the IT potential, in this case of expert systems, for international marketing purposes. Erdener Kaynak and $\mathrm{K}$. Venkataraman develop a set of criteria for evaluating the use of expert systems. This set is then applied to the type of decisions in international marketing, for example which country, region and market, which mode of entry, what decisions on the marketing mix and mode of organization. The authors then come to conclusions about what types of decisions an expert system would help to make. They also review critically existing expert systems for international marketing decisions. Their discussion of the potential of expert systems in the international marketing field fittingly points toward future trends in both IT and marketing and as such, is representative of the main currents running through this theme issue.

Under deregulation and highly competitive conditions, IT is becoming increasingly implicated in marketing in all sectors. We hope that this theme issue will interest business people, academics and students alike, and that more generally it will contribute to our knowledge of how IT can be used more productively to achieve marketing objectives. As ever, the Fournal of Information Technology would be pleased to have any comments or contributions to debates engendered by this theme issue.

Leslie Willcocks Laurent Maruani

\section{The Association for Information Technology}

The role of the Association for Information Technology and its relation with the fournal of Information Technology is under consideration by the executive committee. A proposal for the future of the Association will be put to an extraordinary general meeting to be held early in 1993 at the City University Business School, London. Details of this meeting can be obtained from the Secretary to the Association, Catherine Griffiths at the Kobler Unit, Imperial College, 180 Queen's Gate, London, SW7 2BZ. Telephone 071225 8932, fax 0715897127.

\section{Forthcoming papers include:}

Information technology transfer in econometric forecasting: a pictorial approach. Peter Chong $\mathrm{et} \mathrm{al}$.

Research issues in information systems. Robert Galliers. CASE: A United States usage profile. Geoffrey Howard and Arun Rai.

Management challenges for survival in the 1990s. Garry Hunt.

The economic significance of infrastructural IT systems. Peter Monk.

Software standards: an information requirements framework. Theodora Ngosi and John Jenkins.

Decentralization of information systems in developing countries: power to the people? Geoff Walsham. 